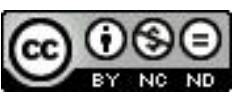

\title{
Uma Introdução às Funções de Variável Complexa no Ensino Médio: uma possibilidade através do uso de animações interativas
}

\section{An Introduction to Complex Variable Functions in High School: a possibility through the use of interactive animations}

\author{
Larissa Weyh Monzon* \\ Maria Alice Gravina**
}

\begin{abstract}
Resumo
Este artigo apresenta a concepção e a construção de produto educacional que trata de números complexos e funções. Na concepção levou-se em consideração o importante papel que tem os sistemas de representação semiótica no processo de aprendizagem da matemática. A construção resultou em site web com coletânea de animações interativas que fazem uso de sistemas dinâmicos de representação algébrica e geométrica. O produto foi testado com turma de alunos do terceiro ano do ensino médio, e os resultados obtidos mostram que com o apoio de ferramentas digitais de mediação semiótica é possível não só introduzir novos conteúdos no programa da matemática escolar, mas também novas propostas de ensino.

Palavras-chave: Números Complexos e Funções. Sistemas Dinâmicos de Representação Semiótica. Registros Algébrico e Geométrico.

\footnotetext{
" Mestre em Ensino de Matemática, Instituto de Matemática da Universidade Federal do Rio Grande do Sul (UFRGS), Porto Alegre, RS, Brasil. Professora de matemática da Escola Municipal de Ensino Fundamental Monteiro Lobato/Novo Hamburgo e Escola de Ensino Médio Nossa Senhora de Fátima/ Sapucaia do Sul. Endereço para correspondência: Rua Lopes Trovão, 333, Torre 1 apto 204, CEP: 93320-500, Novo Hamburgo, RS, Brasil. E-mail: tuquinha.monzon@gmail.com.

** Doutora em Informática na Educação, Programa de Pós-Graduação em Informática na Educação (UFRGS), Porto Alegre, RS, Brasil. Professora do Instituto de Matemática da UFRGS. Endereço para correspondência: Av. Bento Gonçalves 9500, Prédio A, CEP: 91509-900, Porto Alegre, RS, Brasil. E-mail: gravina@mat.ufrgs.br.
} 


\begin{abstract}
This paper presents the design and construction of an educational material that focuses on complex numbers and functions. The design of the material took into account the important role of semiotic systems of representation in the process of learning mathematics. The construction resulted in a web site with a collection of interactive animations that make use of dynamical systems of algebraic and geometric representation. The product was tested with a group of students in the third year of high school, and the results show that, with the help of digital tools of semiotic mediation, it is possible not only to introduce new mathematics subjects in school, but also new forms of teaching and learning.
\end{abstract}

Keywords: Complex Numbers and Functions. Dynamic Systems of Semiotic Representation. Algebraic and Geometric Registers.

\title{
1 Introdução
}

Dentre os conteúdos que fazem parte do programa da matemática escolar, estão aqueles que podem ser trabalhados, de forma natural, em situações que os tornam mais interessantes, tais como aquelas de caráter interdisciplinar ou de resolução de problemas. Mas, há, também, conteúdos com um forte componente abstrato, visto que as situações de aplicações estão além daquelas que podem ser tratadas na matemática escolar. Dentre esses conteúdos, incluímos o assunto números complexos.

No período de realização do Mestrado em Ensino de Matemática, a primeira autora deste artigo, como professora de Ensino Médio, se colocou o desafio de responder as perguntas: a) como tornar o estudo de números complexos mais interessante para os alunos? b) como implementar um estudo introdutório de funções de variável complexa no ensino médio, fazendo intensa transição entre aspectos algébricos e geométricos? As perguntas foram respondidas na dissertação Números complexos e funções de variável complexa no Ensino Médio - uma proposta didática com o uso de objetos de aprendizagem, apresentada no Programa de Pós Graduação em Ensino de Matemática do Instituto de Matemática da UFRGS, em abril de 2012. Como parte do trabalho da dissertação, foi construído o site Números Complexos, um produto que contém animações interativas, tratando de representações de números complexos, de operações com números complexos e de funções de variável complexa, disponível em <http://www.ufrgs.br/espmat no link Biblioteca Virtual>. O produto foi usado na experiência de ensino, em turma do terceiro ano do Ensino Médio, que validou a proposta didática. 
Neste artigo, inicialmente, tratamos do importante papel que os sistemas de representação (linguagem natural, signos e figuras) têm na aprendizagem da matemática. Depois, apresentamos o produto Números Complexos com suas diferentes animações interativas, e buscamos mostrar o quanto as manipulações dinâmicas dos sistemas de representação podem ajudar no processo de aprendizagem. Os resultados positivos da experiência realizada nos permitiram validar o produto, e é assim que nos sentimos confiantes para fazer a sua divulgação.

\section{Os sistemas de representação e a aprendizagem da matemática}

É de forma recorrente que encontramos na literatura pesquisas sobre o importante papel dos sistemas de representação semiótica no processo de aprendizagem da matemática ${ }^{1}$. Conforme Ernest (2006), sendo a semiótica o estudo dos signos que participam em diferentes contextos das atividades humanas, é natural considerar o processo de aprendizagem da matemática também sob esta perspectiva. Ernest avança na definição do que seria um sistema semiótico no contexto específico da matemática, explicitando três componentes: um conjunto de símbolos que são expressos através da fala ou do texto, e do desenho; um conjunto de regras de produção de signos, incluindo, aqui, aquelas que tratam da organização do discurso que faz uso da composição de signos; um conjunto de relações entre os signos e seus significados. Essa definição procura abarcar as características dos textos, símbolos e desenhos que se integram ao discurso lógico que produz e cristaliza o conhecimento matemático.

Usando a história da matemática, Duval (2006) observa o quanto o desenvolvimento das representações semióticas é essencial para a evolução do conhecimento matemático, ou seja, os sistemas de representação são parte da produção de novo conhecimento. Mas a preocupação maior desse autor é quanto ao papel dos sistemas de representação semiótica no processo de aprendizagem da matemática. Na sua teoria introduz a ideia de registro: é um sistema que, além de representar conceitos e ideias, tem regras de funcionamento que permitem a realização de processos matemáticos que levam a novos conceitos e ideias². Os objetos matemáticos, no geral, são expressos através de diferentes registros, e dentre eles, destacamos: o registro algébrico com suas regras de funcionamento que, por exemplo, levam às resoluções de equações; o registro

\footnotetext{
${ }^{1}$ Vale, aqui, referir o volume 61 da revista Educacional Studies in Mathematics, inteiramente dedicado a este tema.

${ }^{2}$ Duval esclarece que nem todo sistema de representação é um registro, e esse seria o caso, por exemplo, do código binário ou do alfabeto.
} 
geométrico com regras de tratamento que levam a identificação dos elementos pertinentes de uma figura, e, dentro desse registro, inclui-se o de natureza gráfica dado por sistema de coordenadas cartesianas e curvas que nele são desenhadas; o registro discursivo em linguagem natural, e também com símbolos, com suas regras convencionais de comunicação.

Outro conceito que tem relevância na teoria de Duval (2006) é o de transformação, que explicita o quanto a atividade matemática consiste, essencialmente, de transformações sobre as representações. As transformações se desdobram em dois tipos: tratamentos, caso em que acontecem dentro de um mesmo registro; conversões, caso em que as transformações transitam entre dois diferentes registros. É nas conversões, muito mais do que nos tratamentos, que estão as maiores dificuldades cognitivas dos alunos; e mais, são as conversões que encerram, de modo contundente, os processos que caracterizam a atividade matemática. Um exemplo de dificuldade documentado pelo autor é quanto à conversão da reta desenhada no plano cartesiano (registro gráfico) para sua equação (registro algébrico) e vice-versa.

Por sua vez, o trabalho de Fischbein (1994) apresenta a explicitação da dificuldade nas conversões, quando ele introduz a ideia de conceito figural com dois componentes: o conceitual e o figural. O componente conceitual, com maior ou menor grau de formalismo, se apresenta em linguagem natural e/ ou simbólica; já o componente figural é de natureza visual (forma, posição, tamanho) e se expressa através do desenho. É a fusão adequada desses componentes que garante a construção de ideias geométricas. Diríamos que a teoria de Duval está em linha de continuidade com a ideia de Fischbein e traz avanços no entendimento da complexidade do processo de aprender matemática, pois a sua teoria evidencia que é o trabalho com muitas conversões entre diferentes registros que vai subsidiar a construção do conhecimento.

É pertinente observar que os sistemas de representação tem um duplo papel. A evolução do saber matemático depende de sistemas de representação que cristalizam e geram novos conceitos e ideias, mas são esses mesmos sistemas de representação que devem ser aprendidos pelo aluno, para que ele possa ter acesso ao saber matemático. Ou seja, de um lado tem-se o matemático no processo de criação de representações que veiculam ideias e procedimentos matemáticos; e, de outro lado, tem-se o aluno na situação de aprendiz de conceitos e procedimentos que dependem de entendimento dos sistemas de representação. Segundo Duval (2006, p.126): "o pensamento matemático depende da sinergia cognitiva dos registros (...) a coordenação dos registros fornece como que uma 
extensão das capacidades mentais”, e diríamos que tal constatação se aplica tanto ao matemático quanto ao aprendiz.

É evidente que os sistemas de representação tornam-se mais ou menos versáteis na veiculação de conceitos e processos, dependendo do suporte que se tem a disposição. Hoje, com as mídias digitais, os sistemas se tornam dinâmicos e, assim, facilitam o processo de apropriação de seu funcionamento; e mais, oferecem a possibilidade de manipulações que transitam de um registro a outro.

Mas, mesmo tendo-se o suporte digital para os sistemas de representação, Bartolini Bussi e Mariotti (2008) questionam o posicionamento bastante corrente de que os sistemas de representação, implementados com as mídias digitais, são suficientes para garantir a aprendizagem da matemática. É sob perspectiva vygotskiana, na qual linguagem e signos são meios que dão suporte à internalização - um processo cognitivo de natureza sociocultural que transforma experiências individuais interpessoais em experiências intrapessoais (VYGOTSKY,1998), que as autoras falam nas ferramentas de mediação semiótica. São recursos tecnológicos que incorporam sistemas de representação e que podem mediar processos de aprendizagem da matemática. Mas o que as autoras discutem é que não basta tal recurso para que se dê o processo de aprendizagem, explicando que, por um lado, ao manipular o recurso, o aluno constrói significados individuais, e por outro lado, de antemão, no recurso está contida a intencionalidade de um saber matemático. E a questão que se coloca é: como garantir que a construção dos significados individuais estão na direção do saber matemático? Partindo do pressuposto que é o especialista, no caso o professor, que tem condições de avaliar o potencial de mediação do recurso, reservam a expressão ferramenta de mediação semiótica para indicar um recurso tecnológico a ser usado em situação didática concebida para a aprendizagem de determinado conteúdo matemático - ou seja, o professor já conhece, de antemão, o potencial semiótico do recurso no que diz respeito à construção do saber matemático em questão.

As autoras avançam na caracterização de um possível modelo de situação didática que faz uso de uma tal ferramenta de mediação: inicialmente, os alunos recebem as atividades a serem exploradas e se engajam em manipulações que concorrem para construção de significados individuais; a isto, segue-se momento de construção coletiva de significados, a ser conduzido pelo professor. Esse modelo, tanto no momento da exploração quanto no momento de construção coletiva, considera a importância de esquemas de uso sintonizados com habilidades cognitivas que caracterizam a atividade matemática. Nesse sentido, o modelo 
pressupõe que haja o planejamento das atividades a serem exploradas com o recurso digital, pois é no engajamento às tarefas propostas que progressivamente emergem e se desenvolvem os esquemas de uso. As considerações teóricas das autoras convergem para a tese de que a apropriação dos sistemas de representação digitais e dinâmicos depende de situações didáticas planejadas e é assim que os alunos desenvolvem habilidades para aprender matemática com as ferramentas de mediação semiótica.

Nossa intenção é ir além desse modelo de situação didática. Com a Internet tem-se a explosão da possibilidade de aprendizado com autonomia. É pensando nesse cenário que desenvolvemos o produto educacional a ser apresentado na próxima sessão.

\section{Um produto para o ensino de números complexos e funções}

Foi levando em consideração a importância do sistema de representação semiótica no processo de aprendizagem que iniciamos o trabalho de concepção e construção do produto didático para o ensino de números complexos e funções, tendo clareza sobre a necessidade de que contemple: a) recursos para conversões entre registros; b) recursos para o desenvolvimento de esquemas de uso sintonizados com os procedimentos que caracterizam o pensamento matemático. Conforme já mencionado, o produto resultou no site Números Complexos disponível em <http://www.ufrgs.br/espmat> no link Biblioteca Virtual. Na Figura 1 vê-se a sua interface.

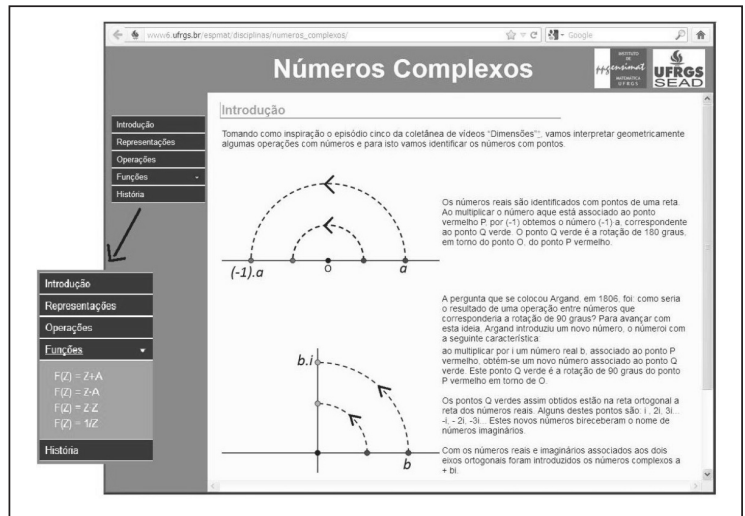

Figura 1 - Site Números Complexos

O material se organiza através de barra de navegação vertical, disposta 
à esquerda da tela e consiste de animações interativas ${ }^{3}$, acompanhadas de explicações e de questões a serem exploradas pelo usuário. No material também foram incluídos recortes da coletânea de vídeos Dimensions: une promenade mathematique ${ }^{4}$; esses recortes são explicações sobre números complexos e funções que, no vídeo, são apresentadas dentro do propósito maior de explorar interações e processos fractais.

Nesta seção, vamos nos deter na apresentação das animações interativas, pois é nelas que está o diferencial do produto. Na concepção das animações, diferentes aspectos foram considerados: procuramos tirar proveito do dinamismo das figuras, e de forma tal que o usuário pode manipular a animação de acordo com seu interesse e dificuldade, transitando entre registros algébrico e geométrico; diferentes graus de liberdade de manipulação foram estabelecidos, conduzindo a aprendizagem de situações simples as mais elaboradas; foi estabelecido um cuidadoso padrão de cor, texto e acabamento e, assim, em cada animação o que se apresenta de novo são, essencialmente, conceitos e processos matemáticos.

A denominação animação interativa trata de registrar o duplo aspecto do material: é uma animação que se produz mediante manipulação de elementos que estão na tela do computador - no caso, números complexos. Na literatura, tal tipo de recurso, vem sendo referido como objeto de aprendizagem: um recurso educacional multimídia, com possibilidades de manipulação e efeitos dinâmicos, voltado para a aprendizagem de um conteúdo específico (WILEY, 2009).

Na concepção do produto também levamos em consideração que somente a animação pode não ser suficiente para o aprendizado. Conforme discutido na sessão anterior, é importante o desenvolvimento de esquemas de uso dos sistemas de representação que concorrem para a construção de saberes; as intervenções do professor, sem dúvida, têm importante papel nesse processo. Mas tivemos o propósito de ir adiante, desenvolvendo um material que pode propiciar a aprendizagem com autonomia. Assim, além dos diferentes graus de liberdade de manipulação, que foram intencionalmente implementados, cada animação é acompanhada de conjunto de questões a serem exploradas, intitulado Para Pensar, e a solicitação é feita de forma tal que o aluno é provocado a manipular a animação e a desenvolver esquemas de uso que ajudam no

\footnotetext{
${ }^{3}$ As animações foram produzidas com o software GeoGebra, de domínio público. Este software está disponível para download em <http://www.geogebra.org/cms/>.

${ }^{4} \mathrm{O}$ vídeo foi produzido por Jos Leys, Étienne Ghys e Aurélien Alvarez e encontra-se disponível em $<$ http://www.dimensions-math.org/Dim_PT.htm>.
} 
entendimento do conteúdo. No conjunto de questões também foram incluídas aquelas que provocam esquemas de uso na direção de raciocínios generalizadores. No quadro teórico de Bartolini Bussi e Mariotti (2008), classificaríamos o produto como uma ferramenta de mediação semiótica, com a característica adicional de favorecer aprendizagens com maior autonomia por parte do usuário.

Nas animações têm-se elementos que são manipuláveis e seu movimento desencadeia efeitos sobre outros elementos. Os primeiros funcionam como variáveis independentes, e são sempre marcados com a cor azul; os elementos que funcionam como variáveis dependentes sempre são marcados em vermelho ${ }^{5}$.

No menu Introdução é apresentado o número imaginário $i$, conforme a ideia de Argand (1768 - 1822) que está no vídeo 5 da coletânea Dimensions: se multiplicar um número real por (-1) corresponde a giro, de $180^{\circ}$, de pontos em torno da origem da reta real, então por que não introduzir um número cujo efeito de multiplicação, nos pontos, corresponda a metade desse giro? Com essa noção de giro de $90^{\circ}$ em torno da origem, tem-se, de forma natural, a característica que define o número $i: i \cdot i=-1$.

Após a introdução do número imaginário $i$, tem-se no menu Representações duas formas de apresentação dos números complexos. $\mathrm{Na}$ primeira animação (Figura 2), os números complexos $\mathrm{Z}$ e W podem ser manipulados e os seus valores se atualizam.

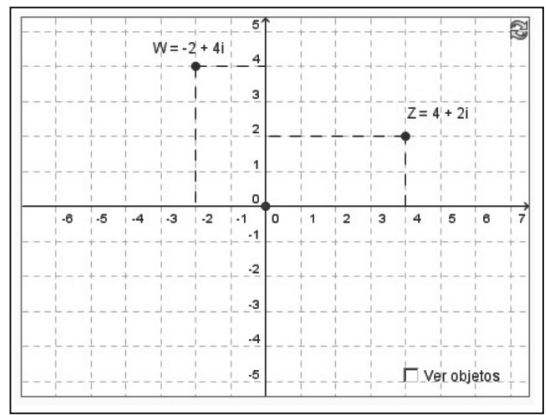

Figura 2 - Número complexo e representação algébrica

As questões do Para Pensar que acompanham a animação tratam de provocar esquemas de uso que levam ao entendimento da representação $a+b$ $i$. Alguns exemplos de questões: encontre números complexos resultantes da

\footnotetext{
${ }_{5}^{5}$ Para visualização colorida das animações sugere-se o acesso ao produto em < http://www.ufrgs.br/ espmat> no link Biblioteca Virtual.
} 
rotação de $90^{\circ}$ do número complexo $2+4 i$; encontre números complexos que tem a parte imaginária igual ao dobro da parte real e identifique que tipo de figura formam estes números complexos? Na primeira questão, inicialmente deve ser localizado o número complexo $\mathrm{Z}=2+4 i$ e após o número W que é a rotação de $90^{\circ}$ de $\mathrm{Z}$, seja via efeito geométrico, seja via multiplicação por $i$; na segunda questão entra em cena o raciocínio generalizador que trata de associar aspectos algébricos do número com aspetos geométricos.

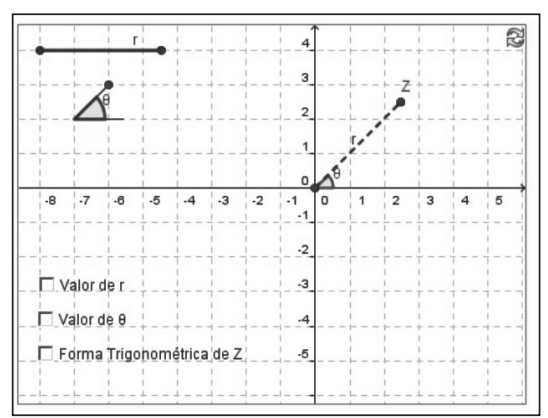

Figura 3 - Módulo e argumento de um número complexo

Na segunda animação (Figura 3), de forma intencional, tem-se a manipulação independente do módulo (r) e do argumento (è) do número complexo Z; estes parâmetros são manipuláveis no canto superior esquerdo da animação e desencadeiam dois movimentos em $\mathrm{Z}$ - ou giro em torno da origem ou afastamento/aproximação da origem. O esquema de uso é dirigido para o entendimento deste par (r, è) e uma das questões do Para Pensar é: encontre números complexos com $r<3$ e $0<\grave{e}<90^{\circ}$ e identifique que tipo de figura formam estes números.

No menu Operações tem-se animações voltadas para o entendimento das operações de soma e multiplicação, sob os pontos de vista algébrico e geométrico. A Figura 4 é a tela da animação que veicula o conceito de soma: os números complexos $\mathrm{Z}$ e $\mathrm{W}$ podem ser manipulados e a soma $\mathrm{Z}+\mathrm{W}$ acompanha as alterações. A animação também disponibiliza os valores de $\mathrm{Z}, \mathrm{W}$ e $\mathrm{Z}+\mathrm{W}$ e os triângulos retângulos que explicam a soma geométrica (ao selecionar-se a caixa Ver detalhes). 


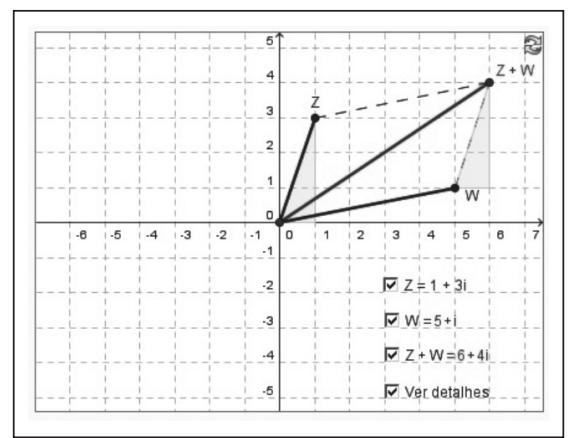

Figura 4 - Soma de números complexos

Uma das questões que acompanha a animação com a intenção de provocar esquemas de uso é: encontre $Z$ e $W$ em pelo menos três situações de forma a obter $(Z+W)=3+3 i$. Observamos que a solicitação feita obriga o aluno a manipular os números complexos $\mathrm{Ze} \mathrm{W}$, mantendo sob constante atenção a interpretação geométrica da soma. Na Figura 5 tem-se uma possível escolha dos números $\mathrm{Z}$ e $\mathrm{W}$.

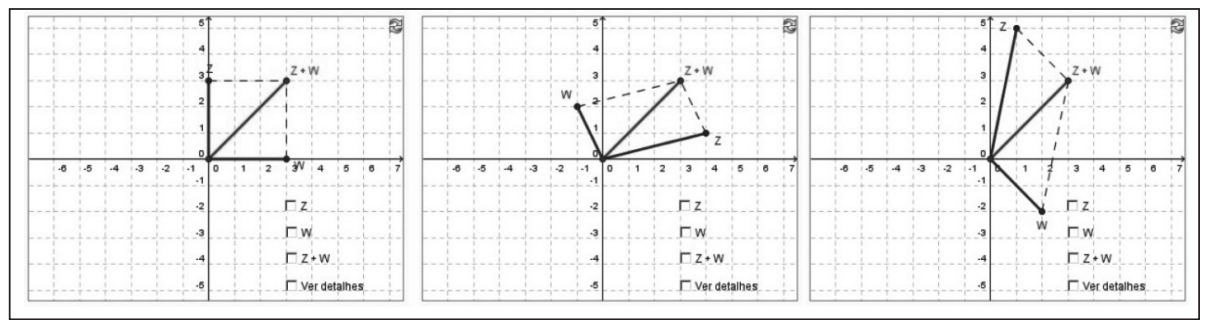

Figura $5-\mathrm{O}$ número complexo $\mathrm{Z}+\mathrm{W}=3+3 i$

Duas são as animações que tratam da multiplicação de números complexos. Na primeira, ilustrada na Figura 6, os círculos pontilhados servem para provocar esquema de uso para identificação da relação entre rotação e multiplicação de números complexos.

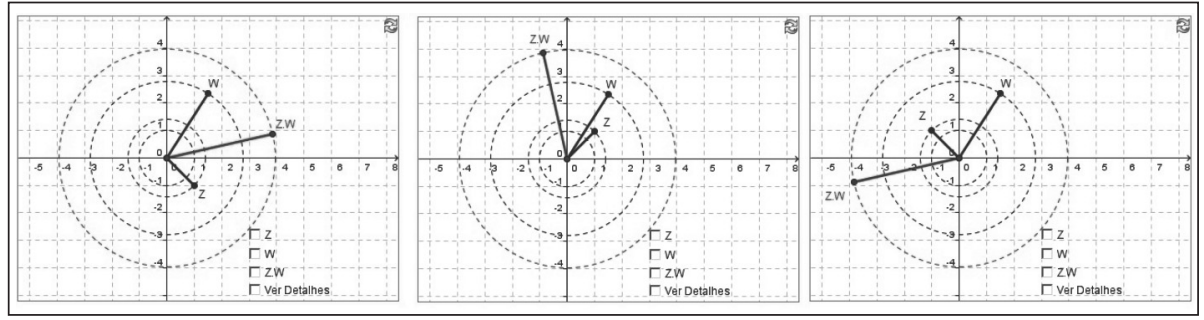

Figura 6 - Rotação e multiplicação de números complexos 
No dinamismo tem-se que, conforme $\mathrm{Z}$ percorre um determinado círculo azul, o produto resultante Z.W percorre o círculo vermelho determinado por um número $\mathrm{W}$ fixo ${ }^{6}$. O dinamismo da animação, como antes, potencializa perguntas generalizadoras e prepara para o entendimento do produto de dois números complexos via movimentos de rotação e/ou homotetia.

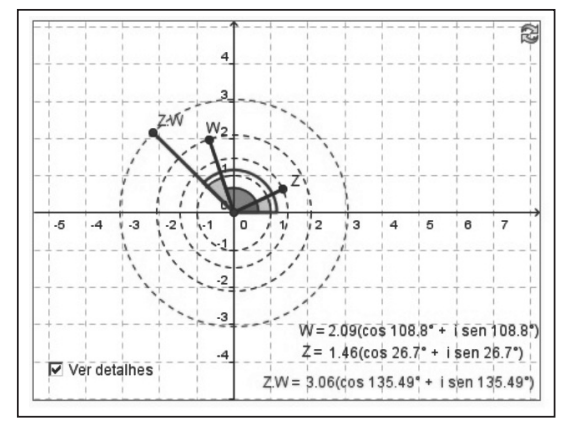

Figura 7 - Multiplicação via forma trigonométrica

Na segunda animação, relativa à multiplicação, é introduzida a expressão $\mathrm{Z} \cdot \mathrm{W}=r \cdot q[\cos (\theta+\beta)+i \operatorname{sen}(\theta+\beta)]$, sendo $(\mathrm{r}, \theta) \mathrm{e}(\mathrm{q}, \beta)$, respectivamente, o módulo e argumento de $\mathrm{Z}$ e W, conforme ilustra a Figura 7. Essa animação provoca esquemas de uso para o entendimento do produto de números complexos via módulo e argumento. Exemplos de algumas questões colocadas para o usuário: encontre $Z$ e $W$ em pelo menos em três situações diferentes de forma que $Z \cdot W=2\left(\cos 135^{\circ}+i\right.$ sen $\left.135^{\circ}\right)$; encontre $Z$ e $W$ em pelo menos em três situações diferentes de forma que o módulo de $Z$. Wé igual a um.

$\mathrm{O}$ quarto menu da barra de navegação do site, denominado Funções, trata de uma introdução as funções de variável complexa, com ênfase nos aspectos geométricos. Nesse menu poucas são as ideias realmente novas, pois os pré-requisitos para o entendimento das funções $\mathrm{F}(\mathrm{Z})=\mathrm{Z}+\mathrm{A}, \mathrm{F}(\mathrm{Z})=\mathrm{Z}$.A, $\mathrm{F}(\mathrm{Z})=\mathrm{Z} . \mathrm{Z}$ e $\mathrm{F}(\mathrm{Z})=1 / \mathrm{Z}$ (são estas que estão disponíveis no menu) são as representações dos números complexos e as operações.

Para cada uma das funções listadas acima se tem duas animações. $\mathrm{Na}$ primeira delas, pode-se fazer a manipulação da variável independente $\mathrm{Z}$ em determinado conjunto fixo no domínio, e deve ser, então, observado o comportamento da variável dependente $\mathrm{F}(\mathrm{Z})$. Na Figura 8 temos a primeira animação da função $F(Z)=$ Z.A e como antes, tem-se a convenção para o uso

\footnotetext{
${ }^{6}$ Novamente, para visualização colorida das animações sugere-se o acesso ao produto em <http:// www.ufrgs.br/espmat> no link Biblioteca Virtual.
} 
das cores - a variável independente $Z$ é marcada em azul e a variável dependente $\mathrm{F}(\mathrm{Z})$ azul é marcada em vermelho ${ }^{7}$.

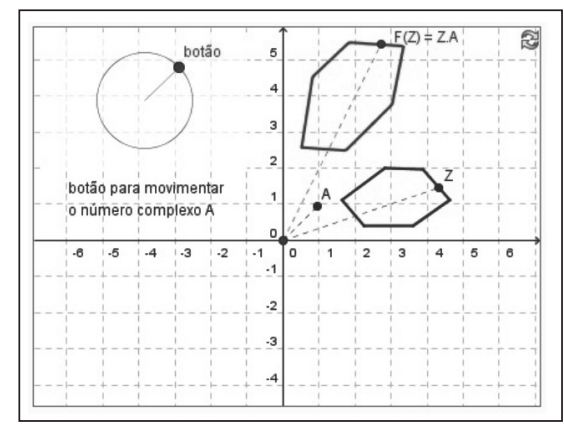

Figura 8 - A função $F(Z)=$ Z.A agindo no polígono azul

Ao deslocar-se $\mathrm{Z}$ no polígono menor tem-se, em sincronia, o movimento de $\mathrm{F}(\mathrm{Z})$ e o dinamismo da animação evidencia o efeito produzido pela transformação que produz o polígono maior - uma rotação seguida de dilatação. É intencionalmente que a manipulação do parâmetro A é feita no canto superior esquerdo da animação, pois com esse esquema de uso os alunos são provocados a entender que para cada valor do número complexo A tem-se uma determinada transformação, que é a composta de uma rotação com uma homotetia. As questões que acompanham a animação também provocam na direção desse entendimento, e, a título de exemplo, transcrevemos algumas delas: a) encontre 3 valores de A para que $F(Z)$ tenha o efeito de rotacionar de $90^{\circ}$ o polígono azul; b) 3 valores de A para que $F(Z)$ tenha o efeito de reduzir pela metade o polígono azul.

Na segunda animação cabe ao usuário fazer a escolha de estratégias de exploração, pois o número complexo $\mathrm{Z}$ pode ser movimentado com liberdade. Nessa animação é possível usar o recurso Habilitar Rastro para melhor observar o comportamento de Z e F(Z), conforme Z é manipulado. Na Figura 9 tem-se o efeito da transformação $F(Z)=Z$.Z quando $Z$ percorre um segmento horizontal azul e quando percorre um quadrado azul. Vê-se no efeito do dinamismo que o comportamento de $\mathrm{F}(\mathrm{Z})=\mathrm{Z}$.Z é bem mais complicado que o comportamento de $\mathrm{F}(\mathrm{Z})=$ Z.A.

\footnotetext{
${ }^{7} \mathrm{O}$ domínio e a imagem da função estão sendo representados no mesmo plano complexo; este é o tipo de representação usada na coletânea de vídeos Dimensions.
} 


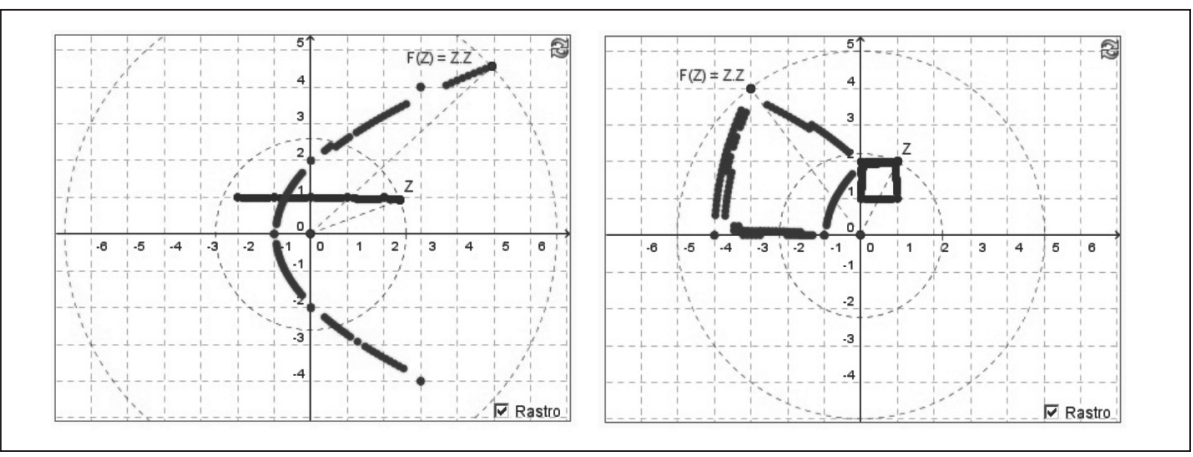

Figura 9 - A função $F(Z)=Z . Z$

$\mathrm{Na}$ apresentação do produto procuramos mostrar o quanto as diferentes animações interativas têm intencionalidade de aprendizagem. Vale realçar a diferença que existe entre esse tipo de recurso e um software no qual se pode trabalhar com muitos conteúdos de matemática, mas nos quais a aprendizagem depende muito das orientações do professor. Na linha de pesquisa que trata do processo de ensino e aprendizagem através de suportes digitais (software, objetos de aprendizagem, animações interativas) diríamos que estamos avançando na direção da aprendizagem com autonomia. Isso porque o usuário tem uma ferramenta que dá suporte a explorações, inicialmente, feitas sob a orientação de questões provocativas. As questões contribuem para o desenvolvimento de esquemas de uso e, assim, o usuário pode prosseguir com outras manipulações, na direção de perguntas generalizadoras que dificilmente se colocariam frente a material didático na forma de texto estático.

\section{Uma experiência com o produto e os resultados}

O produto foi testado com turma de terceiro ano do Ensino Médio noturno, em escola da rede estadual no município de Campo Bom, RS, em 2011. Foram onze encontros, distribuídos em um mês, totalizando 12 horas, e participaram 26 alunos. Os encontros aconteceram no laboratório de informática da escola, onde havia disponível um computador para cada aluno.

O próprio menu de navegação do produto definiu a sequência de atividades implementada na experiência. A rotina de trabalho, nos diferentes encontros, assim se organizou: inicialmente, aconteceu a exploração individual das animações, orientada pelas questões do Para pensar; então, os alunos 
redigiram suas respostas na Folha de Atividades entregue pela professora ${ }^{8}$, contendo as mesmas questões exploradas. Esse material, junto com as observações registradas pela professora, constituiu o material de análise da experiência e de validação do produto. Os vídeos sobre o conteúdo foram assistidos pelo grande grupo no início da atividade; nas exibições dos vídeos, grande foi a atenção dos alunos, o que indica que esse recurso poderia ser mais utilizado nas aulas de matemática. Ao longo dos encontros, as intervenções da professora foram, essencialmente, para esclarecer dúvidas dos alunos; em poucos momentos foram feitas intervenções no grande grupo e, no geral, os alunos avançaram nas atividades com bastante autonomia.

A experiência permitiu constatar que o produto é adequado para desencadear processo de aprendizagem que contempla trabalho com os registros algébrico e geométrico. E mais, foi possível observar que, a partir da manipulação das animações, os alunos foram constantemente provocados nas conversões de registro e, assim, desenvolveram esquemas de uso na direção do ensino almejado - entender as ideias matemáticas em diferentes sistemas de representação. No que segue, destacamos alguns dos momentos que evidenciam esse resultado.

De início, apontamos que a introdução do conceito de número complexo através da ideia de Argand fez com que os alunos, de imediato, colocassem em relação os registros algébrico e geométrico, e aqui foi fundamental a explicação apresentada no video Dimensions. Quanto ao uso da animação que trata da representação de número complexo, trazemos como ilustração a resolução que os alunos apresentaram para a questão: encontre os dois números complexos resultantes da rotação de $90^{\circ}$ do número complexo $2+4 i$. Alguns alunos identificaram geometricamente, via manipulação na animação, os números correspondentes a rotação de $\mathrm{Z}=2+4 i$; outros fizeram a multiplicação $i . \mathrm{Z}$ e i.Z e, então, localizaram esses números na tela da animação.

Nas questões provocativas quanto a raciocínios generalizadores (que tipo de figura formam os números complexos com parte real igual à parte imaginária?; que tipo de figura formam os números complexos que tem parte imaginária igual ao dobro da parte real?) os alunos manipularam $\mathrm{Z}$ e $\mathrm{W}$, controlando a relação entre componentes real e imaginária, e identificaram as retas passando pela origem que responde as perguntas. Novamente, vê-se que a manipulação da animação propicia esquemas de uso que colocam em ação os registros algébrico e geométrico.

\footnotetext{
${ }^{8}$ A professora é a primeira autora do artigo. Uma caraterística do Mestrado Profissionalizante em Ensino de Matemática do IMUFRGS é ser o professor o próprio investigador, no trabalho de dissertação.
} 
Quanto aos conceitos de módulo e argumento de número complexo Z, a possibilidade de manipular na animação, de forma independente os dois parâmetros, evidenciou que a alteração do primeiro aproxima ou afasta $\mathrm{Z}$ da origem, e que a alteração do segundo resulta em giro de $\mathrm{Z}$ em torno da origem. Comparada com uma apresentação estática desses conceitos, na animação temse o diferencial das dinâmicas imagens visuais.

Nas animações relativas às operações, as explorações conduzidas pelas questões Para Pensar exigiram dos alunos raciocínios matemáticos muito diferentes daqueles que se fazem presente nos tradicionais exercícios de somar e multiplicar números complexos. Isso porque o processo de exploração potencializa perguntas generalizadoras. Por exemplo, para responder a questão: encontre $Z$ e $W$ em pelo menos três situações de forma a obter $(Z+W)=$ $3+3 i$, alunos puderam observar, geometricamente, que aumentos nos valores parte real/parte imaginária de Z implicam em equivalente diminuição nos valores parte real/parte imaginária de $\mathrm{W}$ e, foi depois dessa constatação, que trataram de apresentar valores específicos para $\mathrm{Z}$ e W. Vê-se, nessa atitude, esquemas de uso na direção de raciocínios generalizadores.

Uma vez entendidas as operações com números complexos, os alunos trabalharam sem maiores dificuldades com a função $\mathrm{F}(\mathrm{Z})=\mathrm{Z}+\mathrm{A}$. Diríamos que a ideia realmente nova no menu Funções é que, diferentemente das funções de uma variável real, o entendimento do comportamento da função não pode ser registrado em um gráfico, visto que o conjunto de pontos na forma $(Z, F(Z))$ está no espaço de dimensão quatro. Assim o entendimento do comportamento da função exige a análise da ação de F sobre certos subconjuntos do seu domínio. Com a primeira animação, os alunos exploraram o efeito da transformação sobre conjunto de números complexos que formam um polígono e, aqui, o esquema de uso provocado pelas questões visava o entendimento do papel do número complexo A, o que direcionou os alunos para o trabalho com família de funções a um parâmetro. Na segunda animação, agora com liberdade para movimentar A e Z, os alunos trabalharam com questões provocativas quanto a raciocínios generalizadores.

A título de exemplo, trazemos uma das questões: faça $A=2$ - $3 i$ e localize $Z$ para que $F(Z)$ tenha partes real e imaginária iguais. Essa questão poderia ser resolvida via raciocínio puramente algébrico, mas estando frente à animação, os alunos naturalmente trataram de localizar um primeiro valor de Z e, feito isso, continuaram com as manipulações de modo a obter novos valores de Z, e assim identificaram a reta formada pelo conjunto solução. 
De uma forma geral, foi possível observar que frente às animações interativas, acompanhadas das questões Para Pensar, os alunos se colocaram em situação de exploração que conduziu ao desenvolvimento de esquemas de uso cada vez mais elaborados e na direção de resoluções dentro de espírito generalizador. É importante que se diga que, no momento de elaboração das questões, foi preciso antecipar, com atenção, os esquemas de uso que seriam provocados, e esse é um dos aspectos que contribuiu para que o produto se mostrasse propício para aprendizagem com bastante autonomia.

\section{Considerações finais}

Os resultados obtidos com a experiência que fez uso do produto educacional Números Complexos indicam que a tecnologia digital pode muito ajudar na compreensão de conceitos e ideias matemáticas que não fazem parte do programa de matemática da escola. Com esse produto é possível ampliar o universo das funções que podem ser estudadas na escola. E, vale observar, o estudo dos processos interativos com funções de variável complexa, tão simples como $\mathrm{F}(\mathrm{Z})=\mathrm{Z} . \mathrm{Z}+\mathrm{A}$, é um assunto de pesquisa do século $\mathrm{XX}$, que deu origem ao entendimento dos fractais e de suas apreciadas figuras. Por si só, esse fato pode tornar o estudo dos números complexos mais interessante.

\section{Referências}

BARTOLINI BUSSI, M. G.; MARIOTTI, M. A. Semiotic mediation in the mathematics classroom: artifacts and signs after a Vygotskian perspective. In: ENGLISH, L. et al. (Eds.). Handbook of International Research in Mathematics Education, second revised edition, Lawrence Erlbaum: Mahwah, NJ. 2008. p.746-783.

DUVAL, R. A cognitive analysis of problems. of comprehension in a learning of mathematics. Educational Studies in Mathematics. Dordrecht: Kluwer Academic Publisher, n. 61, 2006 p.103-131.

ERNEST, P. A semiotic perspective on Mathematical Activity. Educational Studies in Mathematics. Dordrecht: Kluwer Academic Publisher, n. 61, 2006 p. 67-101.

FISCHBEIN, E. The theory of figural concepts. Educational Studies in Mathematics. Dordrecht: Kluwer Academic Publisher, v. 24, n.2, p. 139-162, 1994. 
LEYS, J.; GHYS, E.; ALVAREZ, A. Dimensions: une promenade mathématique. Disponível em: <http://www.dimensions-math.org/Dim_PT.htm>.Acesso em: 20 jul. 2012.

MONZON, L. W. Números Complexos e funções de variável complexa no ensino médio: uma proposta didática com uso de objeto de aprendizagem. 2012. 134f. Dissertação (Mestrado Profissionalizante em Ensino de Matemática) - Instituto de Matemática da Universidade Federal do Rio Grande do Sul, Porto Alegre, 2012.

VYGOTSKY, S. Y. Linguagem, desenvolvimento e aprendizagem: Lev Semenovich Vigotskii, Alexander Romanovich Luria, Alex N. Leontiev. 6. ed. Tradução de Maria da Penha Villalobos. São Paulo: Ícone, 1998. (Coleção Educação Crítica).

WILEY, D. A. Connecting learning objects to instructional design theory: a definition, a metaphor and a taxonomy. 2009. Disponível em: <http://reusability.org/ read/chpters/wiley.doc>. Acesso em: 27 jul. 2011.

Submetido em Agosto de 2012. Aprovado em Março de 2013. 